\title{
ENTRE O VIVER E O REPRESENTAR: O LUGAR ÉTICO E ESTÉTICO DA DIREÇÃO TEATRAL NA CENA BRASILEIRA CONTEMPORÂNEA
}

BETWEEN LIVING AND ACTING: THE ETHICAL AND AESTHETICAL ISSUES OF THEATRICAL DIRECTION IN THE CONTEMPORARY BRAZILIAN SCENE pela Escola de Comunicação da UFRJ (ECo) e Licenciado em Letras com habilitação em Português/Inglês e suas respectivas Literaturas pela Faculdade Formação de Professores da UERJ (FFP). Possui Especialização em Comunicação e Semiótica pela Universidade Estácio de Sá (UNESA). Recentemente, concluiu o Mestrado (2017) em Teoria da Literatura e Literatura Comparada pelo Programa de Pós-Graduação em Letras (PPGL) do Instituto de Letras da UERJ e iniciou o Doutorado (2017) no mesmo programa e curso.

RESUMO: O presente trabalho tem por objetivo pensar o lugar da direção teatral como um exercício de escuta sensibilizada no conjunto de transformações que cercam a cena contemporânea brasileira. Para analisar os discursos das minorias que tomam parte no sensível propõem-se releituras de aspectos políticos, históricos e sociais para compor uma estética da existência que se constrói na cena teatral. Tomamos para análise duas experiências de montagem: Transegun de Cuti, e Mulheres de pape/ (texto de própria autoria). A conclusão in dica não só o lugar da direção, mas também a cena teatral, como uma prática de ensaiar o presente para reavivar processos de incessantes prática de ensaç

PALAVRAS-CHAVE: direção teatral; política da cena; cena brasileira contemporânea; processo de criação artística.

ABSTRACT: The main goal of this paper is to think the place of theatrical direction as sensitized exercise of listening in the set of transforABical dict: The main god of this paper is to think the place of theamations that surround the Brazlilan contemporary scene. In order to we propose readings of political, histo tal and social aspe sensitive, we propose readings of political, historical and social aspects to compose an aesthetic of the pexistence which is constructed in the theatical by Cuti, and Mutheres de papel (author's own text). The conclusion by Culi, and Mulheres de papel (author's own text). The conclusion indicates not only the place of direction, but also the theatrical scene, as a practice of rehearsing the present to revive processes of incessant

KEYWORDS: theatrical direction; politics of the scene; contemporary Brazilian scene; artistic creation process 
1. Convém destacar algumas divergências entre os historiadores de teatro quanto a esta afirmação, pois a existência de muitos diretores de companhias de teatro, em específicos momento da historia, como Shakespeare questão, pobida. Nossa afirmacão ét tomada com bassa anitraçá de Bernard Dort (2013) e de JeanJacques Roubine (1984).

\section{RASCUNHOS INICIAIS}

A figura do encenador, inventada pela modernidade no fim do século XIX, é posta à desconstrução a partir da década de 1960 do século XX. ${ }^{1}$ A conjuntura política que se desenha no movimento da contracultura põe em xeque a figura unitária do "grande criador" como um mestre/autor da cena, responsável pela organização semântica do espetáculo.

Os movimentos políticos e universitários que marcaram Maio de 1968 revelam-se fundamentais na alternância de microconjunturas, uma vez que o teor político das manifestações leva ta mbém os grupos de teatro às ruas. Desta forma, o coletivo se coloca como unidade pluralizada, ecoando as vozes que vão conferir à nova cena tea tral o seu caráter múltiplo, "a cena do grupo".

Tem-se, portanto, o cenário de uma produção artística marcada por muitas vozes que negociam a orga nização semântica. Forma-se, assim, uma cena, cuja emancipação, segundo Bernard Dort (2013), não se realiza apenas na representação como um lugar de significação (não como uma tradução ou decoração de um texto), mas ta mbém a partir de uma emancipação progressiva dos diferentes componentes que a constituem.

[...] a representação se abre para a ativação do espectador e se reconecta com o que é talvez a vocação do teatro: não de encenar um texto ou organizar um espetáculo, mas de ser uma crítica em processo de significação. A interpretação reencontra todo o seu poder. Enquanto construção, a teatralidade é o questionamento do sentido. ${ }^{2}$

Sendo assim, este artigo se constrói com base nas indagações sobre o lugar que a direção teatral pode ocupar na atualidade, principalmente quando se põe em evidência a questão da representatividade e da visibilidade dos grupos violentamente minorizados pelos discursos hegemônicos da elite branca e patriarcal brasileira. Este trabalho se debruça sobre duas experiências de direção que marcaram minha formação: ${ }^{3}$ Transegun, de Cuti, em 2016, e Mulheres de papel (dra maturgia própria), em 2017.

Transegun é uma peça publicada na coletânea Dois nós na noite e outras peças de teatro negro-brasileiro, editada pela Eboh Editora e Livraria em 1991. A coletânea é assinada por Luiz Silva (que assume Cuti como nome artístico). O Grupo Caixa Preta, de Porto Alegre, realizou uma montagem do texto bem recebida pela crítica em 2003. O texto está estruturado em três atos, em que cada um apresenta determinado número de quadros. A peça não apresenta temporalidade cronológica, estando a quebra do tempo diretamente relacionada a uma tentativa de representar a circularidade presente na vida humana. A dramaturgia de Cuti toma como ponto de partida um grupo de teatro
2. $\mathrm{DORT}$, A representação emancipada, p. 55
3. O uso da primeira pessoa do discurso ocorrerá, algumas vezes, durante o desenvolvimento deste trabalho, até porque participei diretamente das apresentações aqui discutidas: em Transegun, atuei como assistente de direção e em Mulheres de papel, estive na direção e na finalização da dramaturgia. A vivência nos dois processos constitui um desafio, pois eu - homem branco e classe média - não estava em meu

"lugar de fala". O desafio foi o

de ressignificar minha posição

e minha função nos processos, entendendo de que maneira eu poderia contribuir e cooperar pa a realização dos espetáculos.
EM TESE
BELO HORIZONTE
v. 24
N. 1
JAN.-ABR. 2018
VALENTIM. Entre o viver e o representar [...]
P. $75-95$ 
4. Apesar de a proposta indicar a realização de uma leitura nomatizada, e possivel dizer que um espetáculo cênico. Contamos com elementos cenográ́ficos, indumentárias cenograficos, indumentárias, iluminação, Mesmo com o texto encadernado em mãos, propusemos marcações que auxiliaram os atores a conferir que auxiliaram os atores a conferir
organicidade à cena. A leitura teve apresentação única no Teatro Municipal de Niterói, no dia 30/05/2016.

5. Apresentado nos dias 07,08 e 09/11/2017 na Escola de Comunicação da UFRJ (Botafogo/ RJ). Além de apresentações únicas realizadas no II Festiva Interuniversitário de Cultura FestFIC 2017 (Flamengo/RJ), dia $11 / 11 / 2017$, e no Centro Cultural Municipal José Bonifácio (Gamboa/ $\mathrm{RJ})$, dia 17/11/2017. engajado em uma montagem para ser apresentada no Dia da Consciência Negra, paralela mente a esta premissa, questões relativas à formação da subjetividade negra dos integrantes ocupam a cena, estabelecendo também diálogos com a imagem do negro no processo histórico brasileiro. Neste trabalho, tomamos para análise uma apresentação do texto realizada no $8^{\circ}$ Ciclo de Leituras Dramatizadas de Niterói, ${ }^{4}$ ocorrida no Tea tro Municipal da cidade referida.

Mulheres de papel é uma experimentação cênica universitária; um exercício feito de retalhos, colagens e recortes de recortes. A cena é um mosaico que tem por objetivo único expor o corpo em cena para falar das violências que o cercam. Corpos femininos que compartilham experiências e modelam dra maturgicamente os fragmentos retalhados e trazidos para a sala de ensaio. À direção, coube apenas a sensibilização do olhar. O "lugar de fala" é delas; tinha que ser delas. Esse projeto foi concebido para ser apresentado na XVII Mostra de Teatro da UFRJ, ${ }^{5}$ em 2017.

Os dois processos de montagem, aqui referidos, trouxeram consigo dois desafios: 1 . Testar o ofício da direção como território da sensibilização - a escuta sensibilizada e democratizada, desfazendo hierarquizações na concepção do espetáculo; e 2. Entender esse lugar do outro e de que forma ele ressoa os cantos de sua própria experiência.
A partir das experiências de montagens supracitadas, evidencia-se que a direção tea tral é, antes de tudo, um exercício ético que se debruça constantemente sobre o "pensar" e, por consequência, sobre o nosso processo de transformar o mundo e a nós mesmos. Ao pensar a questão ética, a pesquisadora Leila Domingues Machado (1999) retoma a ideia foucaultiana de liberdade, referindo-lhe fatores históricos e modos de ser. "Enquanto ultrapassamento das formas dadas, a liberdade seria o exercício de um questionar crítico das variadas e a nônimas formas de dominação". ${ }^{6}$ Para a pesquisadora, "a liberdade é a condição de ser da ética e essa é a forma assumida pela liberdade".

O que se coloca no jogo da direção é a liberdade criadora capaz de gerar transformações, afetos e modos de se ler realidades existentes. Pensar a direção como espaço de partilhas, ou como efeito do partilhar, envolve a formulação de uma estética da existência nos moldes do pensamento de Michel Foucault (2014 [1984]) por envolver a dimensão da experiência e os riscos que dela se subentendem. Da mesma forma, pode-se tomar ta mbém a própria questão ética, lendo a vida como uma obra de arte ou uma distância entre o que somos e o que poderíamos ser, para falar como Machado (1999).

$\mathrm{Na}$ entrevista intitulada "Uma estética da existência", Foucault afirma que "[...] o sujeito se constitui através de práticas de sujeição ou, de maneira mais autônoma, através de
6. MACHADO Ética, p. 159

7. Idem, p. 160. 
8. FOUCAULT, Uma estética da existência, p. 284.

9. MACHADO, Ética, p. 155 práticas de liberação, de liberdade, como na Antiguidade - a partir, obviamente, de um certo número de regras, de estilos, de convenções que podemos encontrar no meio cultural". 8

Fato é que, ao se colocar como escuta para o outro, neste processo de constituição de sujeitos, a abertura à vivência de alteridades se faz necessária, não como apropriação de si ou do outro, mas a partir da produção de afetos. Leila Domingues Machado retoma também a filosofia espinosiana para indicar que "os corpos e as ideias produzem e são produzidos nas afecções”.

Desta forma, toma mos as reflexões sobre ética formuladas por Machado (1999) para propor uma articulação com a prática político-artística. A direção teatral é, portanto, o lugar de atravessa mentos que possibilita m viver a experiência da produção de diferenças, seja com relação a si mesmo, seja nas relações com o mundo. E, a esta definição, pode-se agregar a fala de Foucault dada à entrevista publicada com o título "Verdade, poder e si mesmo", ressignificando o "papel do intelectual", mencionado pelo filósofo, pelo papel da responsabilidade artística:

Meu papel [...] é mostrar às pessoas que elas são muito mais livres do que pensam, que elas tomam por verdadeiros, por evidentes, certos temas fabricados em um momento particular da história, e que essa pretensa evidência pode ser criticada e destruída. O papel de um intelectual é mudar alguma coisa no pensamento das pessoas. ${ }^{10}$

\section{TRANSEGUN: IDENTIDADES EM TRÂNSITO}

O convite para ser assistente de direção de Transegun me foi posto pela própria diretora Erika Ferreira. No primeiro encontro, ela compartilhou o desejo e a importância de encenar a dra maturgia de Cuti, que marcou sua entrada na ATACEN (Associação dos Trabalhadores em Artes Cênicas de Niterói). Em 2016, realiza mos, com o apoio do edital fornecido pela referida associação, a leitura/espetáculo do texto Transegun como parte das atividades do $8^{\circ} \mathrm{Ciclo} \mathrm{de}$ Leituras Dramatizadas de Niterói.

A necessidade de trazer para a cena a representatividade negra motivou a diretora, uma mulher negra, a associar-se ao núcleo de artes do município e assim propor dra maturgias relacionadas à identidade negra brasileira para os ciclos de leitura que ocorrem a nualmente na cidade de Niterói. Em 2017, ela dirigiu uma adaptação de Liberdade, Liberdade, ${ }^{11}$ de Millôr Fernandes e Flávio Rangel; em 2018, está prevista para o segundo semestre a leitura de Sortilégio, ${ }^{12}$ de Abdias do Nascimento.

Transegun marcou a entrada da referida diretora na ATACEN, em 2016. E, mesmo em pouco tempo de trabalho, ela tem se comprometido com um projeto de visibilização
10. FOUCAULT, Verdade, poder e si mesmo, p. 288, grifos meus.

11. O texto original de Millôr Fernandes e Flávio Rangel, em 1965, propõe reflexões acerca de diferentes períodos históricos em que a liberdade foi cerceada ao ser humano. A peça tem forte valor histórico para o teatro brasileiro, pois foi encenada em período de ditadura militar, reforçando o teatro como um ato de resistência política. Com base nestes dados, a diretora Erika Ferreira promove uma adaptação no texto original inserindo vozes negras não presentes na dramaturgia. $O$ intuito expresso pela montagem é o de colocar o artista negro no foco de afirmação do poder político e social. Desta forma, nomes como Nelson Mandela, Abdias Jesus, entre outros, são ina de na reescrita cênica para dar contorno ao olhar nagro dabre contorno ao ol liberdade.

12. O texto de Abdias Nascimento tem forte teor político, pois se coloca como projeto de afirmação da cultura articana como matriz rasileira. 
12. $>>>$ A peça foi inicialmente montada pelo teatro Experimental do Negro (TEN), marcando a forte militância de Abdias Nascimento, nas décadas de 50 e 60, no movimento negro. A encenação do texto foi alvo de muita censura, pois traz o terreiro de candomble como um espaço de reintegração do negro com sua cultura e religiosidade, antes negadas pela formaçāo cristã do protagonista. texto possui duas versoes: uma versão, nos anos finais da ó́ca 1970 (sendo essa nomeada como Sortilégio ll: mistério negro da cena negra no teatro fluminense, característica que recebia pouca (ou pontuais) importância(s) se compararmos os projetos desenvolvidos desde a inauguração da Associação em 1985 e de sua reativação em 2012. Atuar como assistente de direção na produção de Transegun foi um fator importante e crucial não só para entender o projeto artístico de Erika Ferreira, mas também como as relações entre elenco e direção são permanentemente construídas e, mais importante, desconstruídas na sala de ensaio, lugar onde o verdadeiro espetáculo se inicia.

Muitas vezes, os limites entre montagem e dra maturgia se indefiniam, pois o texto de Cuti se desenvolve a partir de uma crise de identidade que ocorre no grupo teatral Viva, um grupo de teatro negro, a partir da inserção de um ator branco, após a morte recente de um de seus integrantes. De forma semelhante, eu me via como um "estrangeiro" frente a um elenco predominantemente negro, estabelecendo comandos e marcações de cena, tendo o total apoio da direção.

Neste processo de criação, a abertura para sugestões do próprio elenco se fazia necessária, pois os personagens criados por Cuti são dotados de complexas idiossincrasias. Em Transegun, o a utor trabalha não só a consciência racial, mas também as contradições presentes nas relações inter-raciais e as relações de poder que marcam formações subjetivas atravessadas pela sexualidade e pela não-aceitação dos padrões de beleza hegemônicos.

A própria dramaturgia exigia, na sala de ensaio, uma atenção especial ao que Leila Domingues Machado propõe:

[...] o outro não entendido como uma unidade separada e exterior a uma outra unidade-eu. A ideia de alteridade não está fundada nas polarizações interior e exterior ou sujeito e objeto. $\mathrm{O}$ outro presente na ideia de alteridade expressa um diferir, uma outra forma diversa da atual. O que também não nos faz pensar o coletivo enquanto um agrupamento social ou a composição de várias individualidades. A coletividade fala de uma série de agenciamentos, formados de materiais de expressão diversos, e que produzem formas - formas-subjetividade, formas-sociedade, formas-nature$\mathrm{za}$, formas-conhecimento etc. - ao mesmo tempo que desmancham as formas produzidas e permitem a construção de outras. ${ }^{13}$

Entender as narrativas pessoais dos atores no processo criativo era uma forma de conduzir as construções por eles propostas na interpretação dos personagens de Cuti. Tal processo é fundamental, inclusive, no que tange ao olhar para si mesmo e perceber-se como artista negro na cena brasileira. ${ }^{14}$
13. MACHADO, Ética, p. 153.

14. A diretora Erika Ferreira concedeu entrevista à extinta rádio MPB FM na época de divulgação da leitura dramatizada. Trechos desta entrevista estão disponibilizados no blog "Alguém viu meus óculos?", organizado por uma das antigas apresentadoras da radio.

http://alguemviumeusoculos.

blogspot.com.br/2016/05/teatroentrevista-com-erika-ferreira.html 
15. SILVA, O teatro negro como fonte de memória..., p. 77.
Pesquisador da dra maturgia de Cuti, Emerson de Paula Silva (2015) afirma que Transegun é um texto estético e político, aliando a fruição com a reflexão para ressignificar as vidas reprimidas e postas à margem devido à cor da pele. Cuti se vale da metateatralidade pra expor o teatro como uma linguagem artística carregada de teor político. Passado e presente se entrecruzam para conferir novos significados às memórias e aos demais elementos presentes na tradição das religiões a frobrasileiras.

A dramaturgia é marcada pela circularidade: nascimento e morte não são vocábulos apresentados em oposição, mas como palavras-chave para entender uma (re) existência marcada por recomeços. Emerson de Paula Silva nos diz que a peça pode ser configurada

[...] como uma dança de significados sobre a negritude onde cada cena apresenta uma ginga entre a identidade e a memória, apresentando ora recuos, ora aproximações, fazendo surgir uma coreografia única: a dança da morte (morte física, morte dos conceitos, morte da estabilidade e de verdades já cristalizadas). ${ }^{15}$

A diretora Erika Ferreira, na montagem, destaca a resistência do teatro negro, manejando não só o texto de Cuti como um signo em cena, mas ta mbém fazendo ecoar os ritmos e as composições de artistas da música popular brasileira como Cartola, Pixinguinha, Dona Ivone Lara e Bezerra da Silva. O interesse da direção consiste em investigar particularidades estéticas e tornar visíveis as teorias teatrais que promovem questiona mentos ao saber hegemônico, como propõe Julianna Rosa de Souza ${ }^{16}$ (2017).

Desta forma, retomamos o movimento proposto por Leda Maria Martins (1995), em A cena em sombras, uma vez que entender a subjetividade negra implica mudar o direcionamento do olhar para as margens e para as sombras a que foram relegados os negros pelo discurso branco hegemônico. Assim, entenderemos que as margens não só fala $m,{ }^{17}$ mas ta mbém produzem cantos e discursos que precisam ser ouvidos e ecoados com urgências.

De acordo com a pesquisa de Leda Martins, a ficcionalização dos sujeitos negros possibilita a encenação de "[...] novos perfis e diferentes gravuras para a persona dramática, desvelando e questionando, em seu processo de estruturação, os modelos de figuração tradicionais e o próprio sistema ideológico-social que os cria, induz e celebra”. ${ }^{18}$

Montar a dramaturgia de Cuti implica entender o rompimento que seus escritos propõem com os modos de produção dominantes. O autor, inspirado pelas pesquisas do Teatro Experimental do Negro (TEN), retoma, realça e
16. Atriz e doutoranda em teatro pelo PPGT/UDESC. O estudo neste trabalho, toma, efrido de reflexão a conferência da escritora nigeriano Chimamand Adichie, intitulada "Os perigos da história única". A pesquisadora estende às reflexões ao campo da teoria teatral, de modo a destacar que os saberes hegemônicos que integram o conjunto das nossas teorias $>>>$

17. Em alusão ao estudo de Gayatrì Chakravorty Spivak, publicado com o título de Pode o subalterno falar? (2010)

8. MARTINS, A cena em sombras, $\mathrm{p}$ 201.
EM TESE
BELO HORIZONTE
v. 24
N. 1
JAN.-ABR. 2018
VALENTIM. Entre o viver e o representar [ ...]
P. 75-95 
22. A escolha por dramaturgias europeias foi proposital para do que nos é dado como clássico. do que nos é da fragmentos, descontextualizar as obras para formar um corpo estranho na sala de ensaio. As discussões iniciais estavam concentradas na produção de diferenças para, em seguida entender os contextos que a dramaturgia nos indicaria. Apropriar-nos dos fragmentos foi crucial para entender as formas de desmontagem do "clássico" assim, compormos um ética da apropriação (ideia trabalhada ao longo deste trabalho atraves do manifesto do Claire Fontaine) para ressignificar modos de composição e existências, abrindo nossa escuta para as coisas já colocadas em termos artisticos e a melhor maneira de recorrer a elas no . significados e percepções. a utobiográfica, no intuito de buscar um ponto de encontro entre ator e personagem. Com isso, procuramos experi mentar estados corporais e a vivência de cada personagem/ narrador em cena. $\mathrm{O}$ processo privilegiou a experiência do "ser/sentir-se feminino", narrada por cada atriz, para composição de um espetáculo cuja temática é a violência simbólica e o tratamento do corpo como objeto. Os relatos pessoais ampliaram a dimensão crítica da narrativa, que teve por escopo o desajuste entre o mundo representado na peça e o mundo como o conhecemos.

A opção pela estética embebida de fontes latinas se dá, desta forma, através do jogo de percepção: o fantástico é delineado como forma de resistência e imaginação em período de extremos, sobretudo no contexto ditatorial la tino- americano. Destaca mos tais influências, no que concerne à exploração de um universo próprio, das reconfigurações de tempo e de espaço, além da inserção de corpos estra nhos materializados em contextos predeterminados.

CAMINHOS ENSAIADOS: O CORPO, O ESTRANHO E A

\section{APROPRIAÇÃO A LA READY-MADE}

A narrativa Mulheres de papel foi criada a partir de fragmentos de textos clássicos, ${ }^{22}$ podendo-se citar, como exemplo, A tempestade, de Shakespea re, A dama do mar e $O$ pato selvagem, de Ibsen, e Deirdre of the sorrows, de John Millington
Synge. Os recortes selecionados foram apropriados e costurados em um grande mosaico. Tivemos por respaldo o manifesto Em vista de uma prática Ready-Made, do grupo francês Claire Fontaine, ${ }^{23}$ para expor o tom da colagem proposta e reafirmar o comprometimento ético de ressignificar os trechos a partir das leituras realizadas pelas atrizes na sala de ensaio. Cada referência foi tomada e reunida, de modo a destacar diferenças na maneira de se compreender o corpo como um espaço e como um objeto em uma sociedade desigual e violenta. À cena foi incumbida a releitura das incertezas que se impõem ao cotidiano, explorando o imaginário do espectador como meio de exaltar a importância das diferenças e do combate à violência simbólica imposta aos corpos estranhos pela ordem econômico-social.

$\mathrm{Na}$ sala de ensaio, uma aldeia de mulheres surgiu. Recortes de jornais, transcrições de entrevistas, toda e qualquer informação referente à violência contra um corpo feminizado, nos serviram de matéria dramatúrgica. Quebras no plano da fábula foram importantes para distanciar os relatos selecionados e trazidos para cena.

A pesquisa de Silvia Federici (2017) sobre mulheres, corpo e acumulação primitiva, publicada com o título Calibã e a bruxa, foi o fio de costura para os retalhos que formaram a nossa dramaturgia. Federici nos propõe a releitura dos desdobramentos do capitalismo (passado e presente)
23. O grupo Claire Fontaine é um coletivo de arte de Paris, criado em 2004, formado pela italiana Fulvia Carnevale e pelo inglês James Thornhill. A autora furtou o seu nome de uma marca popular de cadernos escolares e diante disso declarou-se uma artista readymade.
EM TESE
BELO HORIZONTE
v. 24
N. 1
JAN-ABR. 2018
VALENTIM. Entre o viver e o representar [...]
P. $75-95$ 
pela perspectiva feminista. Um dos pontos abordados pelo estudo da historiadora, e que se manifesta de modo mais intenso nas cenas arquitetadas, foi o tópico "Colonização e Cristianização". Neste ponto, Federici apresenta um estudo sobre o Novo Mundo: a mulher bruxa no continente americano.

A história do corpo e da caça às bruxas que apresentei é baseada em uma hipótese que pode ser resumida na referência a "Calibã e a bruxa", personagens de $A$ tempestade, símbolos da resistência dos índios americanos à colonização. A hipótese é precisamente a continuidade entre a dominação das populações do Novo Mundo e das populações da Europa, em especial as mulheres, durante a transição do capitalismo. Em ambos os casos, populações inteiras foram expulsas de suas terras pela força, houve um empobrecimento em grande escala e campanhas de "cristianização" que destruíram a autonomia das pessoas e suas relações comunais. Também houve uma influência recíproca entre dois processos, por meio do qual certas formas repressivas que haviam sido desenvolvidas no Velho Mundo foram transportadas para o Novo e depois reimportadas para a Europa. ${ }^{24}$

A história de violência e opressão, que a colonização nos fornece, traz também a possibilidade de pensar a aldeia, em Mulheres de papel, como um corpo prestes a ser invadido, violado. A colonização da América Espanhola, por exemplo, é reverberada na cena, sobretudo no que tange à exploração das riquezas naturais, as resistências do povo colonizado e a demonização da cultura local para promover a expansão do Cristia nismo: "destruí-los ou proibir seu culto era uma forma de atacar a comunidade, suas raízes históricas, a relação do povo com a terra e sua relação intensamente espiritual com a natureza". ${ }^{25}$

Em cena, temos um grupo de mulheres que cultua a Grande Mãe e a ancestralidade. Na aldeia, a relação de confiança entre elas é abalada apenas quando a obsidiana, um a muleto de proteção, é roubada. Logo, elas tomam ciência da invasão que se aproxima. O clima de tensão e incerteza paira sobre toda a cena. A aldeia-corpo, sujeita à iminente invasão, remete à metáfora de Federici: "na fantasia europeia, a América em si era uma mulher nua, sensualmente reclinada em sua rede, que convidava o estrangeiro branco a se aproximar". ${ }^{26}$

A imagem do "estrangeiro" é mencionada na cena, causando determinada a mbiguidade. Tomado como referência da dramaturgia de Ibsen, A dama do mar, o estrangeiro que povoa as lembrancas da personagem Ellida foi desdobrado em dois para Mulheres de papel: é o colonizador trazido pelo navio espanhol e que viola o corpo dela, mas ta mbém 
27. Canção composta por Charles Aznavour, em 1972, para o álbum musical /diote je t'aime. é refletido na figura do personagem Estranho que circula a aldeia, não pertencendo a lugar nenhum.

Não se sabe qual é o pertencimento desta figura estranha que não é macho e nem fêmea, estando em um entre-lugar. Existe uma identificação entre o Estranho e Ellida mais pelo sentimento comum de "desajuste" que pelo desejo propriamente dito. $\mathrm{Na}$ sala de ensaio, entendemos que a melhor forma de conferir uma leitura à figura a mbígua seria através da metáfora animal. Assim, o a tor que deu corpo à pesquisa da personagem não só rapidamente identificou a mbiguidade como um caminho de leitura, como investiu em três anima is para compor a corporeidade dela Nas primeiras cenas, ele se apresentava como um pássaro depois, um tigre; e, por último, uma serpente.

Apesar de não pertencer a lugar nenhum, resquícios de um corpo feminizado surgiam em cena. Ele expressava identificações com aquela aldeia e, diferentemente do seu oposto, queria uma vida harmoniosa e coletiva com elas. Durante o processo, optamos por aproximar a figura do Estra nho com a de uma travesti como forma de trazer para cena outra potência política de um corpo feminino. A composição de Charles Aznavour, Comme ils disent, ${ }^{27}$ coube como base para a criação de um discurso, não da travest em si, mas da sensibilização de um corpo pulsante, ressig nificando a si próprio enqua nto suporte de significados.
Tais recortes e interpretações nos abriram um universo de possibilidades para rascunhar formas de resistências e (re)existências enqua nto sujeito marginalizado, enqua nto corpo-outro, em uma cultura opressora. Tendo-se o fantástico como propulsor, exploramos o reconhecimento de si e do outro, como resposta a uma comunicação perdida em tempos de extremos e de predominante violência aos “corpos estranhos”, resgatando as bases de um diálogo necessá rio ao convívio social. Desta forma, a costura que a pesquisa de Federici (2017) une os retalhos de nossa investigação, destacando a resistência como política de existência.

A caça às bruxas, porém, não destruiu a resistência dos povos colonizados. O vínculo dos índios americanos com a terra com as religiões locais e com a natureza sobreviveu à perseguição devido principalmente à luta das mulheres, proporcionando uma fonte de resistência anticolonial e anticapitalista durante mais de quinhentos anos. Isso é extremamente importante para nós no momento em que assistimos a um novo assalto aos recursos e às formas de existência das populações indígenas. Devemos repensar a maneira como os conquistadores se esforçaram para dominar aqueles a quem colonizavam, e repensar também o que permitiu aos povos originá rios subverter este plano e, contra a destruição de seu universo social e físico, criar uma nova realidade histórica. ${ }^{28}$ 
29. CLAIRE FONTAINE, Em vista de uma prática Ready-made, p.12.

30. $/ d e m$, p. 36.

31. Idem, ibidem
Descobrir em si os mecanismos de resistências: uma forma de mergulhar na pluralidade do que se é. O manifesto publicado pelo grupo Claire Fontaine destaca o caráter plura que permeia a política do ser. Ponto que se expande para o objeto artístico: um múltiplo em si. Investir na coletividade como estratégica de criação e descoberta deste "eu" que se firma em raízes flutuantes implica uma automática desestrutura que rege não só os artistas da cena, mas ta mbém os elementos que compõem a própria cena. Federici salienta que a resistência se manifesta na reafirmação de si: resisto pelo que sou. O grupo Claire Fontaine destaca a resistência pela coletividade: "a construção de si mesmo sempre foi uma tarefa coletiva, uma questão de interferência e resistência, da distribuição de competências e da divisão de tarefas". ${ }^{29}$

Esta é uma das premissas para se defender a sobreposição do múltiplo ao individual na criação artística. O grupo francês prega a descontextualização do objeto, pois é necessário que o espectador adentre o "[...] metafísico terreno baldio que se estende entre as metáforas e as metonímias" ${ }^{30}$ $\mathrm{O}$ a utor do ready-made é, nas leituras do grupo, "[...] aquele que se coloca, humildemente, a escutar a potência, contida em cada objeto, em se tornar obra de arte, ele é o príncipe encantador que supostamente acorda a beleza adormecida no artigo industrial" 31 .
Para finalizar esta seção, cabe aqui uma retomada à montagem de Transegun com o intuito de destacar uma figura ta mbém "estrangeira" e sempre apropriada na narrativa: o personagem Aldo. Na dramaturgia de Cuti, Aldo é o integrante do grupo que falece antes do tempo presente da narrativa, aparecendo nas lembranças dos integrantes como um fantasma. Assumidamente homossexual, Aldo é o outro presente na ausência, confrontando certezas e dilemas éticos que cercam as narrativas de cada personagem ali narrado.

Na montagem, a direção de Erika Ferreira optou por dividir o personagem entre um ator e um bailarino, já que o texto de Cuti indica a presença constante desse fantasma nos quadros que abrigam as ações. A escolha da direção ta mbém se deu em virtude de duas propostas de leituras sobre o mesmo personagem (uma do ator e outra do bailarino) que, embora manifestadas em linguagens distintas, conferiram certa coerência aos nossos objetivos em cena. Foi possível, desta forma, garantir a presença constante do personagem, cuja dança circular abre e encerra nossa montagem. Ator e bailarino ora se espelham ora se afastam na mistura presente/passado, evidenciando o não-pertencimento para trazer a certeza do que se é e, consequentemente, desconstruir certezas tomadas como verdadeiras. 
De modo semelhante, o personagem "estranho" se comporta na narrativa Mulheres de papel. Ambos os personagens, utilizados como um recurso de "contraponto", reafirmam ta mbém o espaço da cena como produtora de diferenças, no intuito de deslocar significados e justapor discursos. Assim, põe-se em evidência o múltiplo que habita as singularidades e contesta verdades dominantes. E nesse jogo ta mbém é possível observar que, na esfera política, os sujeitos ficcionalizados que sofrem das mesmas opressões podem ta mbém se contrapor. O jogo capaz de opor oprimido contra oprimido é traduzido, por exemplo, no confronto Guardiã e Estranho em uma das cenas de Mulheres de papel.

GUARDIÃ (ordenando às aldeãs). Capturem aquela figura estranha que cerca nossa aldeia. Ela é um deles.

Plano intercalado

ESTRANHO. Não sou. E também não sou uma de vocês. GUARDIÃ. O que és, então?

ESTRANHO. Humana. Um terceiro tigre. Sou tão viva quanto as raízes que seguram as árvores e como os pássaros que nos acordam e que voam, voam... Como as águas que vivem correndo depressa, depressa...

GUARDIÃ. És um forasteiro. Você veio deles; você é como eles. Você os trouxe pra cá
ESTRANHO. Não! Fui uma prisioneira deles.

GUARDIÃ. Mostre, então, as marcas das correntes.

ESTRANHO. As marcas deixadas pelas correntes não estão no corpo; estão na alma. Eles me obrigam a ser como eles, mas não sou.

GUARDIÃ. Você é um deles.

$[\ldots]$

GUARDIÃ (abrindo o julgamento). A obsidiana é uma pedra abençoada por nossas ancestrais. Ela nos garante a proteção e a segurança de nossas terras. Desde que você, criatura estranha, começou a circular nossa aldeia, os a marelos ta mbém começaram a se aproximar... E eles estão levando nossa comida, nossas pedras, nossas irmãs... Eles estão escravizando nossos corpos.

ESTRANHO. Não podem me acusar pelo o que eles fazem. Eu já disse que também fui prisioneira deles.

GUARDIÃ. E a pedra? Diga onde está se não foi você quem a entregou para eles?

Estranho permanece em silêncio.

GUARDIÃ. Estão vendo? O silêncio denuncia a culpa!

ESTRANHO. Não sou culpado! ${ }^{32}$ 
O fragmento da cena apresentado revela o jogo de poder estabelecido entre uma figura de autoridade da aldeia e a figura estranha, cuja marca corporal denuncia seu imediato não-pertencimento. Acusado de roubar o a muleto de poder e proteção das aldeãs, a figura permanece presente a todo instante na narrativa ora marcando um contraponto no jogo cênico ora exercendo um espelhamento (por ta mbém ser um corpo marginalizado). O julga mento que se arquiteta na cena citada culmina na identificação do estra nho como um espelho de si: "GUARDIÃ. Eu sou uma estranha; como você". ${ }^{33}$ Desta forma, o trabalho de criação e construção da cena consistiu em materializar nossos próprios preconceitos (elenco e direção) na sala de ensaio, para entender o que nos leva, em nosso próprio cotidia no, a negar as diferenças em nome de nossas próprias verdades. Entender a reprodução sutil e despercebida dos preconceitos foi uma das chaves de construção do trecho destacado. Assim, buscamos uma forma de entendimento do outro como um legítimo outro para entender suas diferenças e como nós nos formamos a partir delas.

Tomando-se o corpo como um espaço de expressão do simbólico, é possível perceber que diversas manifestações violentas são impostas diariamente, seja física ou psicológica, seja nas esferas política, econômica, ou cultural. Por esta razão, foi importante trazer tais propostas cênicas que, direta ou indiretamente, exigiam dos artistas em cena determinada "explicitação de si" como parte do processo de criação. Foi esse ponto que as duas montagens aqui apresentadas exploraram como processo de sensibilização e ampliação da escuta não apenas na relação Ator-Diretor, mas Ator-Elenco-Diretor. Portanto, construir um espaço para partilha, de modo a transgredir hierarquias na composição cênica para fortalecer as relações de confiança, foi fundamental. Houve, pois, uma mescla da experiência dos atores com as personagens pré-concebidas seja pela dramaturgia de Cuti, seja pelos fragmentos dramatúrgicos de Mulheres de papel. Tudo como forma de explorar as inquietações cotidianas e os medos que ameaçam o corpo dentro de uma determinada ordem social.

O lugar da direção no processo foi, desta forma, o espaço de inquietações, provocações, dúvidas, tendo como base a necessidade de escuta do outro para, a partir do elemento diferenciador, encontrar os pontos de ressignificação e desconstrução de toda ordem imposta pela cultura patriarcal, que "assujeita" corpos e modos de ser a modelos raciais, cristãos e econômicos. A proposta esteve, em todas as etapas, amparada no movimento de desconstrução de uma arqueologia da opressão de maneira a ressignificar o próprio corpo enquanto objeto receptáculo e reprodutor de agressões, estereótipos e preconceitos. 


\section{OS RETALHOS DE EXPERIÊNCIA: O JOGO COMO \\ PROCESSO DE SENSIBILIZAÇÃO DA ESCUTA}

$\mathrm{Na}$ sala de ensaio dos processos aqui citados, pode-se destacar duas formas de condução: o jogo como dimensão ritualística no manejo das simbologias (em Transegun e em Mulheres de papel) e a coleta de narrativas pessoais para ressignificá-las no jogo cênico (em Mulheres de papel). Para este percurso, interessava um corpo poético, pulsante, um suporte do sensível atravessado por sensações e sentimentos. Um corpo criador e criatura, produtor de signos e que explodisse em significados. Através do jogo, busca-se recuperar a dimensão ética da vida, muitas vezes renegada em prol da propriedade privada.

A proposição do jogo como ferramenta de construção esteve presente de diferentes maneiras nos dois processos. Em Transegun, as proposições partiram da dramaturgia de Cuti, estando todo o processo ligado aos jogos criados a partir dos estudos de personagens da narrativa. Em Mulheres de papel, o início foi esboçado a partir de proposições do jogo ritualístico, a recriação de um "xamanismo matriarcal", privilegiando-se a sabedoria ancestral e a vida em bandos. Recorremos aos estudos antropológicos e às descrições de estudiosos sobre a vivência em tribos. Desta forma, as proposições de jogo visavam à exploração de um desequilíbrio do grupo frente a uma iminente ameaça de invasão dos colonizadores. Explorar a tensão que o medo e a insegurança impunham foi uma maneira de transpor e ressignificar na cena as violências que cercam corpos na contemporaneidade e as maneiras de se resistir a elas.

Em Mulheres de papel, a vivência do ritual propunha uma imersão na própria individualidade das atrizes, apesar do jogo sempre exigir soluções coletivas. Foi interessante observar como a experiência coletiva faz sobressair a ética pessoal de cada integrante. Tinha-se um corpo e uma ideia produzidos pelos afetos que o jogo provocava - um ponto também trabalhado na pesquisa sobre ética de Leila Machado (1999).

No que tange à imersão subjetiva proposta, inicia-se a pesquisa cênica a partir da investigação do canto. O interesse era buscar um canto particular; um som que brotasse do íntimo e estimulasse a movimentação. Para atingir tal ponto, evocou-se, primeiramente, o silêncio como forma de concentrar a escuta interior... Ouvir os batimentos, os nervos, as correntes sanguíneas. Depois, lenta mente, a escuta foi se expandindo para o externo, os sons a mbientes: do ranger das portas às folhas que se sacudia $m$ com os ventos nas árvores. Começáva mos a produzir a nossa própria música. Uma música particular, íntima. 
34. TURNER, Do ritual ao teatro, $\mathrm{p}$. 144.
Articulações entre "voz" e "som" (estímulos sonoros materializados) foram fundamentais, pois o canto, e a musicalidade a ele associada, operou como um importante veículo para a escuta de si, de modo a a mpliar a consciência corporal e a percepção da sonoridade / experiência sonora. Victor Turner (2015) destaca o valor da experiência no momento do processo experimental (experimentar o outro em seu contexto cultural; viver os símbolos daquele rito, não como fetiche, mas como modo de compreensão do quanto aquilo também desempenha significados que atravessam diferentes experiências). $\mathrm{O}$ antropólogo atenta para a necessidade de se adquirir um conhecimento estrutura mais profundo, em reciprocidade, "[...] na busca de tarefas comuns e de rara transcendência imaginativa de tais tarefas" ${ }^{34}$ Aos poucos, percebía mos que a nossa música era um outro em nós. Um outro que nos permitiu criar um espaço; um espaço demarcado para dar evasão àquela música.

Foram esses estímulos necessários para criar e detalhar aquela aldeia que abrigou nossa narrativa. E, nesta aldeia, o canto crescia e ganhava materializações. Nós buscamos o canto do corpo em fases correspondentes ao ciclo vita das personagens: a criança, a jovem, a mãe, a guerreira e a anciã. A experiência ritualística trazia não só as ressonâncias do corpo, mas os arquétipos e os ritmos dos corpos dançantes. As batidas surdas, na sala de ensaio, entrelaçaram arte e vida através do rito.
Turner, ao discorrer sobre o trabalho de Schechner, destaca que a poiesis é almejada em vez de mimesis, ou seja privilegia-se o fazer, a vivência, em vez da cópia representativa: "o papel cresce junto com o ator; na verdade, ele é 'criado' por meio do processo de ensaio, que às vezes envolve momentos dolorosos de autorrevelação". ${ }^{35}$ As primeiras semanas de criação foram importantes para observar essa ocorrência em nosso processo: a interação entre o elenco, o modo de olhar, tocar, se mover... Ações vividas em contextos que os participantes criavam para si.

Ademais, a temática de Mulheres de papel envolve narrativas de violência e agressão de corpos feminizados na sociedade contemporânea brasileira. Se o processo de criação fosse conduzido de modo integralmente racional, teríamos o potencial lúdico esvaziado e um exercício cênico reduzido à reprodução de "gritos de dor" ou "fases e imagens de desespero". Precisávamos do ritual para destacar o potencial lúdico "do fazer criativo" ignorado pela excessiva racionalização e, ta mbém, para redescobrir uma dimensão ética da vida, esquecida pela ocidentalidade.

Recuperar a ação ritual no teatro é um desafio importante de ser suplantado para a reconfiguração do teatro em suas materialidades específicas. Nesses termos, o jogo é um importante instrumento para devolver o ritual ao teatro. $\mathrm{O}$ isolamento tempo-espaço que o jogo permite instaurar, os

$\begin{array}{llllll}\text { EM TESE } & \text { BELO HORIZONTE } & \text { v. } 24 & \text { N. } 1 & \text { JAN-ABg. } 2018 & \text { VALENTIM. Entre o viver e o representar [ }[. .]\end{array}$


estados de enlevo, de prazer e de ludicidade, situação de jogo e de poesia que o jogo desperta, a relação interpessoal que o jogo promove, e a sedução e o caráter estético inerentes ao fenômeno jogo configuram aspectos que aproximam jogo e ritual. $^{36}$

A reflexão de Roberto Ives Abreu Schettini, acima apresentada, sintetiza nossa busca inicial na primeira fase deste projeto: destacar a vida e suas potências, expressando tais manifestações através da linguagem do corpo. Apenas a expressão não seria capaz de dizer mais do que está inscrito na situação exprimida. É necessário reforçar o sentimento de "pertença" e sobrepor o verbo "ser" ao verbo "sentir" na condução da criação artística.

Como estratégia para unir relatos pessoais e ficção, recorremos à marcação espacial como um significante simbólico. Inspirados na leitura de Matteo Bonfitto (2009) sobre o processo de atuação no teatro de Peter Brook, promoveu-se uma releitura do "tapete" brookiano descrito pelo pesquisador. Bonfitto coloca que o tapete desempenha uma função que ultrapassa de maneira significativa aquela de determinar o espaço de ação cênica, pois "[...] adquiriu potencialidades simbólicas, funciona ndo assim como um elemento que cria um espaço através do qual o inesperado e o desconhecido podem emergir. [...] Ele permite uma concentração interior que leva a um estado menos nervoso. Nós atingimos uma calma trabalhada” ${ }^{37}$ Investigar as construções que permeia m este espaço vazio foi de especial importância, sobretudo se destacar os estímulos e o contexto da dra maturgia como situações preestabelecidas.

Mais do que ter uma função utilitária, o tapete preparou o ator para lidar com o vazio, e consequentemente espaços puderam ser criados não somente através de temas preestabelecidos, mas ta mbém por meio de ações corporais e vocais executadas por membros do CIRT: "Dentro do espaço vazio de Peter Brook, nada bloqueia a imaginação do espectador. Tudo é possível. Um gesto, um grito produzido por um ator é suficiente para criar um lugar, uma situação". ${ }^{38}$

Com isso, um jogo, no que tange à abertura da dramaturgia para a mescla autobiográfica, foi estabelecido. Narrativas particulares sobre os medos, os anseios, as rivalidades e as violências se somaram à história das personagens das mulheres da aldeia de Mulheres de papel. Foi expandida a área do tapete para a expressão dos corpos cênicos, pois a pesquisa de Larissa Elias diz que "[...] o tapete aponta para um formato, mas é um formato que não define uma forma, e por isso oferece a possibilidade do jogo" ${ }^{39}$ Portanto, foi necessário intensificar o potencial da experiência vivida no ato de criação cênica.
37. BONFITTO, A cinética do invisivel, p. 64

38. Idem, ibidem. 
40. Idem, p. 21.

41. BROOK, A porta aberta, p. 97
Com fita crepe, foi desenhado um grande retângulo e estabelecidas algumas situações para que os atores desenvolvessem sua criação. Insistiu-se na "perda” como tema principal. Um por vez adentrava aquele espaço e o contaminava com o seu corpo, sua energia. A única regra proposta no jogo foi o contágio: o ocupante seguinte deveria permitir "deixar-se" conta minar pelos signos produzidos pelo ocupante anterior. Assim, teríamos signos em ressignificação alterados por afetos depositados naquela espacialidade. Um estado de in-significância que, visivelmente, se desdobrava em criações que se sucediam.

Larissa Elias sublinha a importância de "[...] encontrar na simplicidade do tapete um tipo de plenitude e de campo aberto para o acontecimento tea tral, no fluxo das próprias experiências, [o experimento] foi se transformando num movimento de fixação da forma" ${ }^{40} \mathrm{O}$ "tapete" foi também uma das inspirações para a cenografia, nos moldes relatados por Brook, para o espetáculo $A$ tempestade, no livro $A$ porta aberta, "um campo livre para o jogo da imaginação". ${ }^{41}$ A cenógrafa de Brook, Chloé Obolensky, propôs um tapete de areia; meus parceiros de cenografia, um tapete de folhas secas com pequenas concentrações de argila.

O quadro Mulheres de papel foi a aldeia-corpo que se pôs como narrativa das histórias de resistências e (re) existências. Interessante é notar que a própria dramaturgia exigia um cenário vivo e atuante, que interagisse com as circunstâncias trazidas pela cena. O barulho e o cheiro das folhas, bem como a argila que conferia um cheiro de terra molhada ao espaço da cena, convidava o espectador a entrar naquele universo em um forte apelo sinestésico. Explorar a potencialidade que aquele espaço nos permitia era um modo não só de acentuar o caráter épico de nossa criação, mas ta mbém fixar raízes e denotar as formas de pertencimento que cada personagem estabelecia com aquele local.

Buscar formas de pertencimento foi um movimento pensado ta mbém para a concepção do figurino, livremente inspirado na paleta de cores das Yabás, do culto afro-religioso. A referência consistiu em uma tentativa de estabelecer maior aproximação com as matrizes culturais reverberantes desta cultura na nossa. Cabe destacar também que as referências ao culto afro-religioso nos remetem, mais uma vez, à pesquisa de Federici (2017), quando ela desenvolve suas a nálises sobre o processo de demonização do "outro" ao abordar a africanização da bruxa pelo poderio econômico, branco e cristão. As personagens em cena ganham ares de divindades de matrizes a frica nas que, associadas ao efeito de magia produzido pelos figurinos, deslocavam (e confundiam) não só as referências postas em jogo, como 
42. CLAIRE FONTAINE, Em vista de uma prática Ready-made, p. 12 também a percepção das singularidades desenhadas por cada personagem

\section{ENCERRANDO ESTE CAMINHO PARA A ABERTURA DE}

\section{NOVOS CAMINHOS}

O ser humano é um sujeito social e político, tendo o corpo como ferramenta para dar forma às relações sociais. No corpo reside a subjetividade materializada, portanto o discurso hegemônico exige que todas as ma nifestações que envolvem e a travessa $\mathrm{m}$ o corpo estejam em conformidade com os padrões hegemonizados. Fato que desencadeia aos sujeitos transgressores a opressão e a marginalização "Nossos corpos são cruzados por relações de poder e nossos devires são orientados pelos meios através dos quais nos opomos a este poder ou nos colocamos ao seu fluxo". ${ }^{2}$ Transegun e Mulheres de papel são montagens situadas nesta encruzilhada para ressignificar as margens e reafirmar identidades.

A poética das cenas a nalisadas evidenciam corpos constituídos por imagens que se desenham e se reprocessam no percurso cênico. A tarefa de articular as imagens produzidas e postas à significação no jogo cênico implica entender a distribuição dos signos que compõe uma cena emancipada, para falar como Dort (2013). Ta is imagens são retroalimentáveis e estabelecem relações de apropriação, permanecendo no pós-espetáculo, para todos os seus participantes. De modo semelhante, ela nos destaca a importância do corpo múltiplo apontado pelo manifesto do Claire Fontaine (2016): a pluralidade que habita os corpos forma o todo coletivo harmonizado pelas singularidades.

O jogo cênico proposto por Transegun e por Mulheres de papel apela a um reconhecimento da pluralidade, destacando críticas inerentes a uma ética e a uma estética da existência, seja no reconhecimento de si através do outro, seja nos apelos sensíveis que requerem uma escuta para uma sensibilidade à dimensão da vida e à visibilidade dos corpos desprezados (ou objetificados) pelo discurso hegemônico. Forma-se um corpo múltiplo nas cenas que expressam potências de vidas que resistem porque existem.

Teatro não é um exercício sobre si, mas um exercício de alteridade. É entender como este outro te afeta e como você se deixa afetar pelo outro. O lugar da direção teatral pode ser entendido como um exercício de escuta que implica repensar o próprio fazer teatral como uma prática do ensaiar-se no presente da ação enqua nto ser in-significante; um lugar da partilha de um sensível escrito no cruzamento da estética e da política.

O tea tro contemporâneo brasileiro se assume como um experimento que a mbiciona denunciar, sem messianismo, 
43. BENTO, Política da diferença, $\mathrm{p}$. 80. as formas de violência que "assujeitam" corpos e oprimem subjetividades. Uma forma que ultrapassa e ressignifica o já desgastado movimento proposto por muitos grupos - e ta mbém criticado por Berenice Bento (2011) - a questão da mudança eficaz de uma determinada conjuntura, na esfera política, ocorrer somente a través do acionamento da máquina binária: "Homens versus mulheres, negros versus brancos. Movemo-nos em dois mundos: aqueles de sujeitos concretos e o da esfera política, no qual os sujeitos são ficções". ${ }^{43}$

Enfim, o trabalho se coloca como uma escrita política de corpos que, a través dela, ma terializam gestos imbuídos de significação: sua pertença ao mundo. É um fazer dramatúrgico sobre construções de imagens invisibilizadas, através de uma leitura histórica, filosófica e sociológica do corpo reverberando um estado de in-significância para indicar a existência pela pluralidade do que se é e do que se pode ser.

\section{APÊNDICE}

FICHAS TÉCNICAS:

Transegun (2016)

Direção: Erika Ferreira

Assistência de direção: Felipe Valentim

Elenco: Claudia Macedo, Henrique Vieira, Cintia Maria Ricardo, André Elenco: Claudia Macedo, Henrique Vieira, Cintia Maria Ricardo, Andre
Sanaibre, Rhaiany Soares, Withe Vianna, Ivan de Oliveira, Maria de Sanaibre, Rhaiany Soares, Withe
Fátima Bandeira, Kadu Monteiro.
Direção Musical: Sandro Toledo

Músicos: Silvano Marciano, Fábio Pereira e Sandro Toledo Bailarino: Alessandro Fêrcar

Fotografia: Marta Azevedo, Tom Marinho e Tiago Torres Produção: Fernanda Fernandes e Sylvio Moura

lluminação: Sylvio Moura

Mulheres de Papel (2017)

Texto e direção: Felipe Valentim

Orientação: Daniel Marques

Assistência de direção: Anna Padilha

Elenco: Manu Mayrink, Liris Naira, Tairini Félix, Renata Tedeschi e Tiago Torres.

Voz-off: Anna Padilha

Iluminação: Henrique Bueno e Wesley Calcanho

Cenografia: Kelly Malheiros, Nícolas Gonçalves e Miriam Guilarducc Orientação de cenografia: Michele Augusto

Figurino: Isaac Neves, Rafaela Cascaes, Bianca Oliveira e Joyce Cristina

Orientação de figurino: Samuel Abrantes

Produção: Renata Tedeschi, Luiz Buarque e Bernardo Pimentel

Preparação corporal: Flora Bulcão e Raquel Cukierman

Orientação de preparação corporal: Lígia Tourinho

Coreografias: Flora Bulcão

Preparação vocal: Verônica Machado

Pesquisa musical: Felipe Valentim

Músicas e composições: Alexandre Marzullo 


\section{REFERÊNCIAS}

BENTO, Berenice. Política da diferença: feminismos e

transexualidades. In: Leandro Colling, Djalma Thurler. (org.). Stonewall 40+ o quê?. Salvador: UFBA, 2011, v. único, p. 79110.

BONFITTO, Matteo. A cinética do invisível: processos de atuação no teatro de Peter Brook. São Paulo: Perspectiva / FAPESP, 2009.

BONFITTO, Matteo. $\mathbf{O}$ ator compositor: as ações físicas como eixo: de Stanislávski a Barba. São Paulo: Perspectiva, 2013

BROOK, Peter. A porta aberta: reflexões sobre a interpretação e o teatro. Tradução de Antonio Mercado. Rio de Janeiro:

Civilização Brasileira, 2000

CLAIRE FONTAINE. Em vista de uma prática Ready-made. Trad. Aurore Zachayus, Fábio Morais, Lucas Parente, Noara Quintana e Revista Punkto. São Paulo: CLAC, 2016

DORT, Bernard. A representação emancipada. In: Sala Preta, São Paulo, v. 13, n.1, jun/2013, p. 47-55.

ELIAS, Larissa. O tapete e o Bouffes: "forma essencial" na poética de Brook. In: O percevejo, Rio de Janeiro, v.4, n.2, agosto/dezembro 2012, p.1-24.

FEDERICl, Silvia. Calibã e a bruxa: mulheres, corpo e acumulação primitiva. Trad. Coletivo Sycorax. São Paulo: Elefante, 2017.
FOUCAULT, Michel. Uma estética da existência. In: MOTTA,

Manoel Barros da (org.). Ditos e escritos, vol V: ética,

sexualidade, política. Trad. Elisa Monteiro [et al]. Rio de Janeiro: Forense Universitária, 2014 [1984]. (Ditos e escritos 5)

FOUCAULT, Michel. Verdade, poder e si mesmo. In: MOTTA, Manoel Barros da. Ditos e escritos, vol V: ética, sexualidade, política. Trad. Elisa Monteiro [et al]. Rio de Janeiro: Forense Universitária, 2014 [1988]. (Ditos e escritos 5)

MACHADO, Leila Domingues. Ética. In: BARROS, Maria Elizabeth (org.). Psicologia: questões contemporâneas. Vitória: EDUFES, 1999

MARTINS, Leda Maria. A cena em sombras. São Paulo: Perspectiva, 1995

RACIĖRE. Jacques. A partilha do sensível. Trad. Mônica Costa Netto. São Paulo: EXO experimental org.; Editora 34, 2009

ROAS, David. A ameaça do fantástico: aproximações teóricas. Trad. Julián Fuks. São Paulo: Editora Unesp, 2014

ROUBINE, Jean-Jacques. A linguagem da encenação teatral Trad. Yan Michalsky. Rio de Janeiro: Zahar Editores, 1984.

SCHETTINI, Roberto Ives Abreu. Jogo e ritual - Teatralidades contemporâneas na formação do artista/educador/pesquisador. In: BRONDANI, Joyce; et al. (org.). Teatro-máscara-ritual. São Paulo: Editora Alinea, 2012 
SILVA, Emerson de Paula. O teatro negro como fonte de memória

e identidade afro-descendente: análise da peça Transegun, de

Cuti. In: Urdimento. Florianópolis, v. 1, n.24, julho/2015, p. 72-91.

SOUZA, Julianna Rosa de. Personagem negra: uma reflexão

crítica sobre os padrões raciais na produção dramatúrgica

brasileira. In: Revista Brasileira de Estudos da Presença, Porto

Alegre, v. 7, n. 2, maio/agosto 2017, p. 274-295.

SPIVAK, Gayatri Chakravorty. Pode o subalterno falar? Trad.

Sandra Regina Goulart Almeida [et al]. Belo Horizonte: Editora UFMG, 2010

TURNER, Victor. Do ritual ao teatro: a seriedade humana de brincar. Trad. Michele Markowitz e Juliana Romeiro. Rio de Janeiro: UFRJ, 2015.

Recebido em: 10-06-2018.

Aceito em: 15-09-2018 